\title{
NATURALEZA Y HUMANIDAD: DESAFÍOS DE LA ECOBIOÉTICA
}

Fernando Lolas Stepke ${ }^{1}$

Los dos polos en que se desenvuelve la deliberación bioética son los seres humanos y la naturaleza. Entendiendo por ésta, obviamente, la naturaleza inanimada, los seres vivos no humanos que la habitan y la naturaleza artificial creada por influencia humana.

La mayor parte de la reflexión filosófica, cuando de asuntos prácticos se trata, es antropocéntrica. Ya para Kant el ser humano racional es la culminación perfecta del designio divino. Y gran parte de los conceptos habituales en el lenguaje acerca de derechos y deberes, tales como dignidad y respeto, suelen aludir a individuos humanos. No existe una teoría de los deberes que sea aplicable a la naturaleza, que se representa como ciega, sorda, inerte, sin designio.

En los tiempos actuales, el viejo terror a la aniquilación nuclear cede ante los temores por la intrusión de la técnica en la vida humana y apocalípticas visiones de un mundo depredado que experimentará un cambio climático letal; la reflexión ética se concentra en esos dos polos del análisis — sujeto y naturaleza-, como lo manifiestan los artículos incluidos en este número de Acta Bioethica.

Se trata de estudiar los fines, propósitos y medios de la acción humana, la única susceptible de sanción moral. Pues, si bien la naturaleza puede ser tildada de cruel o malvada, nadie de mentalidad occidental le atribuiría propósitos o finalidades. La voluntad de los dioses de la selva, aplacar las iras de las nubes o satisfacer deidades animales, no se cuentan entre las preocupaciones manifiestas de las multitudes en los países europeos o en la América europeizada. Al menos no de manera evidente, pues siempre persisten formas de pensamiento mítico y animismos inconscientes.

En la conciencia occidental, la noción de "individuo" sufre numerosos avatares hasta su culminación en la Ilustración. Bajo las nociones de Enlightenment y Aufklärung, por solo citar dos lenguas cultas (además de la española), la construcción del sujeto moderno se asocia a la luminosidad de la razón, que imita la omnipotencia y omnipresencia de Dios, o la representa entre los mortales. La relación entre la luz, el entendimiento y la bondad está tan hondamente arraigada, que el Sol ha sido objeto de veneración y la luz se vincula al bien. Y el bien, cuando se crea la idea de "razón", consiste en obrar de acuerdo con sus dictados.

La razón reside en individuos. Los conjuntos de individuos, solamente por extensión y metafóricamente, poseen razón o imperativo histórico que explicarían las misiones que algunos pueblos se atribuyeron y atribuyen. Habitualmente, estos pueblos "descubren" sus "misiones" gracias a iluminados profetas o líderes carismáticos que corporizan sus aspiraciones inconscientes. A estos "héroes" dedica Thomas Carlyle un estudio que destaca la importancia de las individualidades en la historia.

Para una ética ecológica es importante destacar que el hecho moral siempre reside en individuos humanos. Cuando se habla de proteger el ambiente, en realidad se piensa en proteger a los seres humanos. El pensamiento utilitarista de Potter, que pedía respetar la biósfera para garantizar la supervivencia de la especie humana, y la "com-pasión" de Jahr, que pedía solidaridad con todo lo vivo, rescatan un núcleo de preocupaciones que se hicieron necesarias cuando la profunda ligazón de ser humano y mundo se fracturó y se constituyeron individuos, más como límite y resistencia que como receptáculo y expresión de todo lo vivo. Hasta la conciencia, según propone Julian Jaynes en su clásico libro sobre su origen, podría explicarse como una fractura de la mentalidad antigua, señalada hasta la Edad Media por misteriosas correspondencias y "signaturas" que revelaban que el ser humano está "sujeto" a la Naturaleza. El sujeto moderno es, contrariamente, su opuesto; domina a la Naturaleza y hace de ella su hogar a

1 Director Acta Bioethica. Centro Interdisciplinario de Estudios en Bioética, Universidad de Chile Correspondencia: flolas@uchile.cl 
través de la técnica y el lenguaje (la más excelsa de las técnicas sociales).

La "dimensión humana del ambiente" está presente en los trabajos sobre eco-bioética, la que se tiene presente hablando de determinantes sociales o biológicos, comparando usos y prácticas en distintos grupos humanos o analizando las leyes, esas expresiones de voluntad colectiva que mandan, prohíben o permiten.

Sigue siendo el tema: cómo determinar fines "buenos" y "razonables" y como lograr armonizarlos con medios "buenos" y "razonables". La relación entre fines universales, propósitos concretos y medios adecuados es la tarea de todo esfuerzo normativo y el acicate para toda reflexión. La razón no solamente debe proponer fines, también debe proveer medios. Y no todos los fines, y por cierto no todos los medios, satisfacen los deseos de bienestar humano en distintos periodos históricos. Las culturas son conjuntos de fines implícitos; se heredan con la leche del biberón y se modulan por la creatividad de sus miembros y las situaciones que enfrentan.

Se encuentra, en esta edición de Acta Bioethica, consideraciones sobre el entorno clínico, reflexiones sobre intervenciones genéticas, apuntes sobre formas de mejorar el contacto entre personas en la relación terapéutica y análisis de los desafíos éticos y jurídicos que propone el ambiente natural. Son todas aportaciones de personas que encuentran en esta publicación un lugar adecuado para su difusión y discusión.

A punto de cumplir cuatro lustros, Acta Bioethica mantiene su carácter de amplio foro y de punto de encuentro de perspectivas. 